\title{
Molecular Diversity from Selected Zingiberaceae
}

\author{
Hasnah Mohd Sirat
}

Department of Chemistry, Faculty of Science, Universiti Teknologi Malaysia, 81310 Skudai, Johor, Malaysia

Zingiberaceae is a ginger family, distributed throughout tropics, particularly in South East Asia. In Peninsular itself there are at least 150 species. Several ginger species are used as ingredients in traditional medicine including halia bara (Zingiber officinale var. rubra), turmeric (Curcuma domestica), lempoyang (Z. zerumbet), temu hitam (Curcuma aeruginosa), temu lawak (C. xanthorrhiza), bonglai (Z. cassumunar) and setawar (Costus speciosus). They are usually associated with post-partum treatment after child birth. A number of ginger species, such as the true ginger (Z. officinale), turmeric ( $C$. domestica), lengkuas $($ Alpinia galanga), kantan (Phaemoria speciosa), cekur (Kaempferia galanga) and pelaga (Amomum cardamomum) are used mainly for spices by the Malays, Chinese and Indians. Another economic importance is their usage as ornamental plants, such as Alpinia purpurata, Hedychium coronarium, and Zingiber spectabile. Systematic study on the species are carried out due to the wide ranges of usage, for the production of bioactive compounds useful for agro, pharmaceutical and cosmeceutical industries. This paper will present some of the findings on the phytochemicals of selected plants of Zingiberaceae. These include sesquiterpenoids, diterpenoids, phenolics, flavonoids, diarylheptanoids and phenylpropanoids. Some of these constituents have been found to show some interesting bioactivities, such as antimicrobes, antioxidant, anti-inflammatory and anticancer as well as tyrosinase inhibition activities.

Keywords: Zingiberaceae, phytochemicals, bioactivities. 